\title{
Low-Temperature MOCVD of Chromium Carbonitride Coatings from Tetrakis(diethylamido)chromium and Pyrolysis Mechanism of this Single-Source Precursor
}

\author{
Francis Maury ${ }^{1 *}$ and Franco Ossola ${ }^{2}$ \\ ${ }^{1}$ Laboratoire de Réactivité et Protection des Matériaux, CNRS-INPT, Ecole Nationale Supérieure de \\ Chimie, 118 route de Narbonne, 31077 Toulouse cedex 4, France \\ ${ }^{2}$ Istituto di Chimica e Tecnologie Inorganiche e dei Materiali Avanzati, Area della Ricerca del CNR, Corso \\ Stati Uniti 4, I-35127, Padova, Italy
}

\begin{abstract}
Amorphous chromium carbonitride coatings with a low nitrogen content (3-8 at\%) were deposited by low-pressure MOCVD in the temperature range 573-793 K using $\mathrm{Cr}\left(\mathrm{NEt}_{2}\right)_{4}$ as single-source precursor. This poor nitrogen incorporation is in agreement with the trends predicted by thermochemical calculations. XPS data, resistivity measurements and annealing experiments suggest that the films grown at $573 \mathrm{~K}$ are contaminated by organic species due to incomplete elimination of the ligands. The films deposited at higher temperature crystallize upon annealing at $873 \mathrm{~K}$ to form an orthorhombic ternary chromium carbonitride phase. The major volatile by-products of the MOCVD reaction were analyzed by ${ }^{1} \mathrm{H}$ and ${ }^{13} \mathrm{C}$ NMR. Their amount and the quasi-equimolar $\mathrm{EtN}=\mathrm{CHMe} /$ HNEt $_{2}$ ratio suggest that most of the $\mathrm{NEt}_{2}$ ligands are removed by a stepwise mechanism which probably occurs with other diethylamido complexes of transition metals when they are used as single-source precursors in MOCVD. The incorporation of the metalloid elements in the film is discussed in comparison with recent literature data. (C) 1998 John Wiley \& Sons, Ltd.

Appl. Organometal. Chem. 12, 189-199 (1998)
\end{abstract}

Keywords: single-source precursor; tetrakis(diethylamido)chromium; pyrolysis mechanism; MOCVD; low-temperature deposition; chromium carbonitride thin films; hard metallurgical coatings

Received 30 December 1996; accepted 15 May 1997

*Correspondence to: Francis Maury, Laboratoire de Réactivité et Protection des Matériaux, CNRS-INPT, Ecole Nationale Supérieure de Chimie, 118 route de Narbonne, 31077 Toulouse cedex 4, France.E-mail: fmaury@ensct.fr

\section{INTRODUCTION}

Metal-organic compounds are well known to be less stable than halide derivatives and to provide volatile sources of transition metals. Consequently, they are extensively used as molecular precursors in the chemical vapor deposition process (MOCVD) to deposit, at low temperature, a large variety of thin-film materials for new industrial applications. This is, for instance, an attractive process for the growth of chromium carbide and nitride coatings which are among the most important candidates for the protection of steel components owing to their high hardness, high melting point and good resistance to wear and corrosion.

A key requirement for the successful deposition of a desired phase by MOCVD is the use of a suitably tailored precursor. For the growth of multielement materials, it can be designed for use as a single-source precursor, which means it can supply all the elements required for the formation of the films. Thus, a single-source precursor allows a good control of the gas-phase composition up to the deposition zone and is useful for simplification of the reactor design and processing conditions. However, it appears from a recent critical review on the stringent requirements for metal-organic compounds suitable for MOCVD processes ${ }^{2}$ that progress in the design of metal-organic precursors, and thence further development of MOCVD, both strongly depend on the knowledge of growth mechanisms. The thermal decomposition of metal-organic compounds can take place according to numerous mechanisms and a crucial problem is to control the reaction pathway which leads from the precursor to the thin film.

Although many organochromium complexes containing a variety of $\mathrm{Cr}-\mathrm{C}$ bonds have been used as volatile precursors for MOCVD of chromium 
based coatings ${ }^{3}$ a few chromium precursors containing $\mathrm{Cr}-\mathrm{N}$ bonds have been reported, e.g. $\mathrm{Cr}\left(\mathrm{N}-i \mathrm{Pr}_{2}\right)_{3}{ }^{4}$ and $\mathrm{Cr}\left[\mathrm{N}\left(\mathrm{SiMe}_{3}\right)_{2}\right]_{3}{ }^{5}$ Such amidochromium compounds are not suitable single sources for the growth of chromium nitride coatings since the films are heavily contaminated with carbon. Similarly, in spite of a $\mathrm{MN}_{x}$ cluster core, transition-metal dialkylamido compounds, $\mathrm{M}\left(\mathrm{NR}_{2}\right)_{x}$, were not successfully used as singlesource precursors for the growth of metal nitride, since large amounts of carbon were incorporated into the films, as reported for titanium, and vanadium. ${ }^{8}$ Therefore, deposition of metal nitrides using these precursors requires addition of a large excess of ammonia, as demonstrated for nitrides of titanium, ${ }^{9-17}$ zirconium, ${ }^{9,11,18}$ hafnium, ${ }^{9,11}$ niobium, ${ }^{9,18,19}$ tantalum, ${ }^{9,19}$ vanadium $^{8,9,18,19}$ and molybdenum. ${ }^{18}$ This MOCVD reaction with $\mathrm{NH}_{3}$ has been widely investigated in order to understand the formation of nitride $9,10,13-17$ but pyrolysis of $\mathrm{M}\left(\mathrm{NR}_{2}\right)_{x}$ without any additive is still unclear. $6,7,16,17,20,21$

In this paper, the tetrakis(diethylamido)chromium(IV) complex, $\mathrm{Cr}\left(\mathrm{NEt}_{2}\right)_{4}$ (1), has been employed as single-source precursor to deposit chromium carbonitride thin films by MOCVD. The results are compared with thermodynamic calculations. Its pyrolysis mechanism has been investigated and is discussed to give a further insight into the mechanism of incorporation of the metalloid elements into the films grown using this family of precursors.

\section{EXPERIMENTAL}

\subsection{MOCVD set-up and procedures}

The precursor $\mathrm{Cr}\left(\mathrm{NEt}_{2}\right)_{4}$ was synthesized according to the literature procedure. ${ }^{22}$ Its identification was achieved by comparison with reported spectroscopic data and fully supported by elemental analysis results. It is an air-sensitive liquid at room temperature. This is an advantage compared with solid precursors, such as for instance the related dialkylamidochromium(III) compound $\mathrm{Cr}\left(\mathrm{N}-i \mathrm{Pr}_{2}\right)_{3}$ previously used, ${ }^{4}$ in view of the stability and the control of the gas-phase composition.

Deposition experiments were carried out in a classical horizontal hot-wall Pyrex glass reactor $1.4 \mathrm{~cm}$ in diameter with an isothermal length of $\mathrm{ca}$ $8 \mathrm{~cm}$. The gas streams $\left(\mathrm{N}_{2}\right.$ and $\left.\mathrm{H}_{2}\right)$ were monitored using mass flowmeters. Silicon, glass, alumina and

(C) 1998 John Wiley \& Sons, Ltd. stainless steel plates, $1 \mathrm{~cm} \times 1 \mathrm{~cm}$ each, were used as substrates. The steel substrates were mechanically polished with $\mathrm{SiC}$ paper and then with diamond paste down to a final grade of $1 \mu \mathrm{m}$ and were ultrasonically cleaned in ethanol. All the substrates were cleaned in distilled water, degreased in hot acetone and rapidly put into the reactor under high vacuum $\left(10^{-3} \mathrm{~Pa}\right)$ at $773 \mathrm{~K}$ for about $24 \mathrm{~h}$. A liquid-nitrogen cold trap was placed at the outlet of the reactor to sample the volatile byproducts of the CVD reaction for further analyses. All these operations, e.g. synthesis of 1, MOCVD set-up and sampling of by-products, were performed in a series of glove boxes, with rigorous exclusion of oxygen and moisture.

\subsection{General instrumentation}

The structure of the films was determined by X-ray diffraction $(\mathrm{CuK} \alpha)$ using $\theta-\theta$ and grazing configurations. Their composition was analyzed by electron probe microanalysis (EPMA) using a CAMECA SX50 instrument operating at $10 \mathrm{kV}$ or $5 \mathrm{kV}$ depending on the thickness of the samples. Assuming the film density is close to that of $\mathrm{Cr}_{3} \mathrm{C}_{2}$, the depth of the region probed in these conditions is estimated at approx. 480 and approx. $170 \mathrm{~nm}$, respectively, and the width is lower by a ratio of about 1.3:1. The values reported for the film composition are an average of four to five measurements on different parts of the surface of the samples.

Chemical bonding analyses were performed by X-ray photo-electron spectroscopy (XPS) using a VG Escalab MKII spectrophotometer operating with a non-monochromatized $\mathrm{MgK} \alpha \mathrm{X}$-ray source $(1253.6 \mathrm{eV})$. The measured binding energies were referred to the $\mathrm{Au} 4 f_{7 / 2}$ level at $84.0 \mathrm{eV}$ from a gold standard film. The surface contamination was removed by $\mathrm{Ar}^{+}$sputtering $(4 \mathrm{kV}, 100 \mu \mathrm{A}, 5 \mathrm{~min})$ down to a sputter depth of approximately $30 \mathrm{~nm}^{23}$ The free carbon content of the films was determined from the relative intensity of each component using a curve-fitting computer program and it was defined as the intensity ratio of the free-carbon contribution to the total carbon.

Electrical resistivities of the films grown on glass substrates were measured at room temperature by the linear four-point probe method. The NMR data were recorded on a Bruker 200A instrument.

\subsection{Volatile by-product analysis}

A known amount of a benzene/benzene- $\mathrm{d}_{6}$ solvent 
mixture was introduced in the cold trap at the outlet of the reactor and the resulting solutions were analyzed by ${ }^{1} \mathrm{H}$ and ${ }^{13} \mathrm{C}$ NMR spectroscopy. $N$ Ethylideneethylamine, EtN=CHMe (2), and diethylamine, $\mathrm{HNEt}_{2}(\mathbf{3})$, were fully identified as by-products by comparison with literature data. ${ }^{24,25}$ Quantitative analyses were performed using the standard integration method. ${ }^{26}$ The amounts of 2 and $\mathbf{3}$ trapped during the deposition were calculated from the amount of solvent mixture used, its proton concentration and the relative intensities of the ${ }^{1} \mathrm{H}$ NMR peaks. According to this method, the proton concentration was calculated from the relative intensities of the ${ }^{1} \mathrm{H}$ NMR peaks of a solution obtained by adding a small known amount of $\mathrm{HNEt}_{2}$ to a known amount of the solvent mixture.

When such quantitative NMR analysis of the CVD by-products was not possible because part of 1 passed through the reactor without decomposition [as occurs at low temperature (run 4) and using a stream of carrier gas], the $\mathbf{2 / 3}$ ratios have been calculated on the basis of the ${ }^{1} \mathrm{H}$ integral values. The efficiency of the liquid-nitrogen trap may not allow the complete capture of the most volatile gaseous by-products formed in the CVD process, e.g. hydrogen or light hydrocarbons (if produced), but, since the boiling points of $\mathbf{2}$ and $\mathbf{3}$ are very close $(331-333 \mathrm{~K}$ and $323 \mathrm{~K}$, respectively), it is reasonable to assume that the $2 / 3$ ratios found in the benzene- $\mathrm{d}_{6}$ solutions are representative of the ratios as-produced in the deposition process.

\section{THERMOCHEMICAL CALCULATIONS}

Thermodynamic analysis may provide fruitful information for the optimization of the deposition conditions for the growth of a desired phase. A complex equilibrium calculation based on the minimization of the Gibbs energy of the whole system $^{27}$ was performed for the $\mathrm{Cr}-\mathrm{N}-\mathrm{C}-\mathrm{H}$ system using a computer program to predict the nature of the solid phases formed by pyrolysis of the input gas mixture $\mathrm{Cr}\left(\mathrm{NEt}_{2}\right)_{4} / \mathrm{H}_{2} / \mathrm{He}$. The goal was to find the conditions for which the growth of pure chromium nitride is possible using this singlesource precursor. Kinetics and diffusion phenomena were neglected and the metal-organic precursor was assumed to be fully decomposed in the gas phase; this is supported by further observations. In this method, all the gaseous and condensed species which can be formed in the CVD reaction must be taken into account and the reliability of the calculation depends directly on the validity of their thermodynamic data. Thus, the calculation was possible only after the theoretical determination of the Gibbs free energy of the solid solution $\mathrm{Cr}_{2}\left(\mathrm{~N}_{x} \mathrm{C}_{1-x}\right)$ versus the temperature and the composition. $^{28}$ This was achieved by considering this solid solution as a mixture of the $\mathrm{Cr}_{2} \mathrm{~N}$ and the metastable $\mathrm{Cr}_{2} \mathrm{C}$ phases. The reliability of this approach was fully supported by the good agreement between the theoretical and experimental isothermal $\mathrm{Cr}-\mathrm{N}-\mathrm{C}$ sections. A noteworthy result of this previous work is that calculated isothermal ternary sections have shown that co-deposition of carbon and nitride phases is thermodynamically possible at $800 \mathrm{~K}$, whereas it is not at higher temperature. ${ }^{28}$ As a result, carbon contamination of the films is a drawback of this MOCVD process which is difficult to overcome.

In the present work, the gaseous chemical species $\mathrm{CH}, \mathrm{CH}_{2}, \mathrm{CH}_{3}, \mathrm{CH}_{4}, \mathrm{C}_{2} \mathrm{H}_{2}, \mathrm{C}_{2} \mathrm{H}_{4}, \mathrm{C}_{2} \mathrm{H}_{6}, \mathrm{C}_{3} \mathrm{H}_{4}$, $\mathrm{C}_{3} \mathrm{H}_{8}, \mathrm{C}_{4} \mathrm{H}_{2}, \mathrm{C}_{4} \mathrm{H}_{6}, \mathrm{C}_{6} \mathrm{H}_{6}, \mathrm{CHN}, \mathrm{CN}, \mathrm{CN}_{2}, \mathrm{C}_{2} \mathrm{~N}$, $\mathrm{C}_{2} \mathrm{~N}_{2}, \mathrm{NH}, \mathrm{NH}_{2}, \mathrm{NH}_{3}, \mathrm{~N}_{2} \mathrm{H}_{2}, \mathrm{~N}_{2} \mathrm{H}_{4}, \mathrm{H}, \mathrm{H}_{2}, \mathrm{~N}, \mathrm{~N}_{2}$, $\mathrm{CrN}$ and $\mathrm{Cr}$ and the condensed phases $\mathrm{Cr}, \mathrm{Cr}_{23} \mathrm{C}_{6}$, $\mathrm{Cr}_{7} \mathrm{C}_{3}, \mathrm{Cr}_{3} \mathrm{C}_{2}, \mathrm{CrN}, \mathrm{Cr}_{2} \mathrm{~N}, \mathrm{Cr}_{2}\left(\mathrm{~N}_{x} \mathrm{C}_{1-x}\right)$ and $\mathrm{C}$ were considered in the calculations. Their thermodynamic data were taken from a databank. ${ }^{29}$

Typical results of the calculations are reported in Table 1 . The hexagonal $\mathrm{Cr}_{2} \mathrm{~N}$ phase deposited by CVD at high temperature ${ }^{30}$ is not obtained in the conditions explored using this single-source precursor. The only chromium nitride obtained is the cubic $\mathrm{CrN}$ phase. This is possible only under atmospheric pressure using low mole fractions and a large excess of $\mathrm{H}_{2}$. Clearly, it appears that low pressure facilitates both the formation of chromium carbide $\left(\mathrm{Cr}_{3} \mathrm{C}_{2}\right)$ or carbonitride and contamination by free carbon.

\section{GROWTH AND FILM CHARACTERIZATION}

Typical MOCVD conditions used are reported in Table 2. For deposition runs carried out under reduced pressure, the precursor $\mathbf{1}$ was vaporized at $333 \mathrm{~K}$ into the reactor because it exhibits, at this temperature, a sufficient vapor pressure and it was found to be thermally stable until $c a 395 \mathrm{~K}$ under TG/DTA conditions.

The film compositions reported in Table 2 reveal that the oxygen content is close to the detection limit, except for the sample prepared at low 
Table 1 Theoretical influence of the total pressure $\left(P_{\mathrm{T}}\right)$ and the input mol fraction $(x)$ of $\mathrm{Cr}\left(\mathrm{NEt}_{2}\right)_{4}$ on the nature of the condensed phases deposited at $800 \mathrm{~K}$ under a helium or $\mathrm{H}_{2}$ atmosphere

\begin{tabular}{|c|c|c|c|c|}
\hline \multirow[b]{2}{*}{$P_{\mathrm{T}}(\mathrm{kPa})$} & \multicolumn{2}{|c|}{$\mathrm{Cr}\left(\mathrm{NEt}_{2}\right)_{4} / \mathrm{He}$} & \multicolumn{2}{|c|}{$\mathrm{Cr}\left(\mathrm{NEt}_{2}\right)_{4} / \mathrm{H}_{2}$} \\
\hline & $x=0.5$ & $x=9.9 \times 10^{-3}$ & $x=0.5$ & $x=9.9 \times 10^{-3}$ \\
\hline 0.1 & $\mathrm{Cr}_{3} \mathrm{C}_{2}+\mathrm{C}$ & $\mathrm{Cr}_{3} \mathrm{C}_{2}+\mathrm{C}$ & $\mathrm{Cr}_{3} \mathrm{C}_{2}+\mathrm{C}$ & $\mathrm{Cr}_{3} \mathrm{C}_{2}+\mathrm{C}$ \\
\hline 0.5 & $\mathrm{Cr}_{2}(\mathrm{~N}, \mathrm{C})+\mathrm{C}$ & $\mathrm{Cr}_{3} \mathrm{C}_{2}+\mathrm{C}$ & - & - \\
\hline 1.0 & $\mathrm{Cr}_{2}(\mathrm{~N}, \mathrm{C})+\mathrm{C}$ & $\mathrm{Cr}_{3} \mathrm{C}_{2}+\mathrm{C}$ & $\mathrm{Cr}_{2}(\mathrm{~N}, \mathrm{C})+\mathrm{C}$ & $\mathrm{Cr}_{2}(\mathrm{~N}, \mathrm{C})+\mathrm{C}$ \\
\hline 5.1 & $\mathrm{CrN}+\mathrm{C}$ & $\mathrm{Cr}_{2}(\mathrm{~N}, \mathrm{C})+\mathrm{C}$ & - & - \\
\hline 10.1 & $\mathrm{CrN}+\mathrm{C}$ & $\mathrm{CrN}+\mathrm{C}$ & $\mathrm{CrN}+\mathrm{C}$ & $\mathrm{CrN}+\mathrm{C}$ \\
\hline 50.7 & $\mathrm{CrN}+\mathrm{C}$ & $\mathrm{CrN}+\mathrm{C}$ & - & - \\
\hline 101.3 & $\mathrm{CrN}+\mathrm{C}$ & $\mathrm{CrN}+\mathrm{C}$ & $\mathrm{CrN}+\mathrm{C}$ & $\mathrm{CrN}$ \\
\hline
\end{tabular}

temperature $(573 \mathrm{~K})$. Taking into account the high affinity of chromium for oxygen, this good result certainly originates from the stringent precautions taken during the synthesis of $\mathbf{1}$ and above all from the fact that the MOCVD set-up and the deposition runs were carried out inside a glove box under a controlled atmosphere. The nitrogen content of the films is also very low, although the precursor contains the $\mathrm{CrN}_{4}$ core unit. The chemical composition of the films does not change drastically with the deposition conditions. However, when the growth temperature increases, the nitrogen content slightly decreases while conversely the chromium content tends to increase. The incorporation of nitrogen is slightly higher when the films are deposited under high vacuum, without any carrier gas, rather than using a partial pressure of inert carrier gas. The use of $\mathrm{H}_{2}$ as carrier gas has no significant influence on the nitrogen content of the films.

Unfortunately, attempts to deposit thin films under atmospheric pressure failed because of premature decomposition of $\mathbf{1}$ in the bubbler, which was heated in that case at $363 \mathrm{~K}$ to improve the vaporization rate. However, even if comparison with the thermodynamic prediction was not possible under atmospheric pressure, the relatively high carbon content ( $\mathrm{ca} 30$ at\%), or low nitrogen content ( $c$ a 5 at\%), of the films deposited under reduced pressure is consistent with the trends predicted by thermodynamic calculations (Table 1). This is also in agreement with results reported using the related precursor $\mathrm{Cr}\left(\mathrm{N}-i \mathrm{Pr}_{2}\right)_{3}$ since the films deposited under reduced pressure contained 29 at\% carbon. ${ }^{4}$ Furthermore, there is a parent chemistry between amido complexes of chromium and other transition

Table 2 Experimental conditions and chemical composition of the films deposited by MOCVD using $\mathrm{Cr}\left(\mathrm{NEt}_{2}\right)_{4}$ as single-source precursor

\begin{tabular}{|c|c|c|c|c|c|c|c|c|c|c|}
\hline \multirow[b]{2}{*}{ Run } & \multicolumn{4}{|c|}{ Deposition Conditions } & \multicolumn{4}{|c|}{ EPMA (at\%) } & \multicolumn{2}{|c|}{$\mathrm{XPS}^{\mathrm{b}}$} \\
\hline & $\begin{array}{c}\text { Deposition } \\
\text { Temperature } \\
(\mathrm{K})\end{array}$ & $\begin{array}{c}\text { Total } \\
\text { Pressure } \\
(\mathrm{Pa})\end{array}$ & $\begin{array}{c}\text { Carrier gas/ } \\
\text { flow rate } \\
(\mathrm{sccm})\end{array}$ & Substrate & $\mathrm{Cr}$ & $\mathrm{C}$ & $\mathrm{N}$ & $\mathrm{O}^{\mathrm{a}}$ & $\begin{array}{l}\text { Free } C^{b} \\
(\%)\end{array}$ & $\begin{array}{c}\mathrm{N} 1 s \\
\text { FWHM } \\
(\mathrm{eV})\end{array}$ \\
\hline 4 & 573 & $1.3 \times 10^{-2}$ & 0 & $\begin{array}{c}\text { Glass } \\
\mathrm{Al}_{2} \mathrm{O}_{3}\end{array}$ & $\overline{4}^{\mathrm{d}}$ & $\sim \overline{2}^{\mathrm{d}}$ & $\overline{\sim 11}^{\mathrm{d}}$ & $\overline{114}^{\mathrm{d}}$ & 42 & $\begin{array}{l}2.8 \\
-\end{array}$ \\
\hline 6 & 683 & $1.3 \times 10^{-2}$ & 0 & $\mathrm{Si}$ & 59 & 33 & 8 & $<1$ & 31 & 2.4 \\
\hline 3 & 793 & $1.3 \times 10^{-2}$ & 0 & $\mathrm{Si}$ & - & - & - & - & 32 & 2.4 \\
\hline 1 & & & & $\mathrm{Si}$ & 65 & 29 & 6 & $<1$ & - & - \\
\hline \multirow[t]{2}{*}{9} & 793 & 733 & $\mathrm{~N}_{2} / 418$ & $\mathrm{Si}$ & 64 & 32 & 3 & $\leq 1$ & 45 & 2.0 \\
\hline & & & & $\mathrm{Al}_{2} \mathrm{O}_{3}$ & 64 & 31 & 4 & $\overline{\leq} 1$ & 46 & 2.0 \\
\hline \multirow[t]{2}{*}{10} & 793 & 733 & $\mathrm{H}_{2} / 467$ & $\mathrm{Si}$ & 64 & 32 & 4 & $\overline{\leq} 1$ & - & - \\
\hline & & & & $\mathrm{Si}$ & - & - & - & - & 52 & 2.0 \\
\hline
\end{tabular}

${ }^{a}$ Estimated by difference from $100 \%$.

${ }^{\mathrm{b}}$ XPS data were obtained after $\mathrm{Ar}^{+}$sputtering to remove the surface contamination (sputter depth $\simeq 30 \mathrm{~nm}$ ).

${ }^{c}$ Contribution of the free $\mathrm{C}$ to the $\mathrm{C} 1 s$ peak determined using a curve-fitting programme.

${ }^{\mathrm{d}}$ Values given with a larger uncertainty because of interactions with the substrate resulting from the lower thickness of this film. 


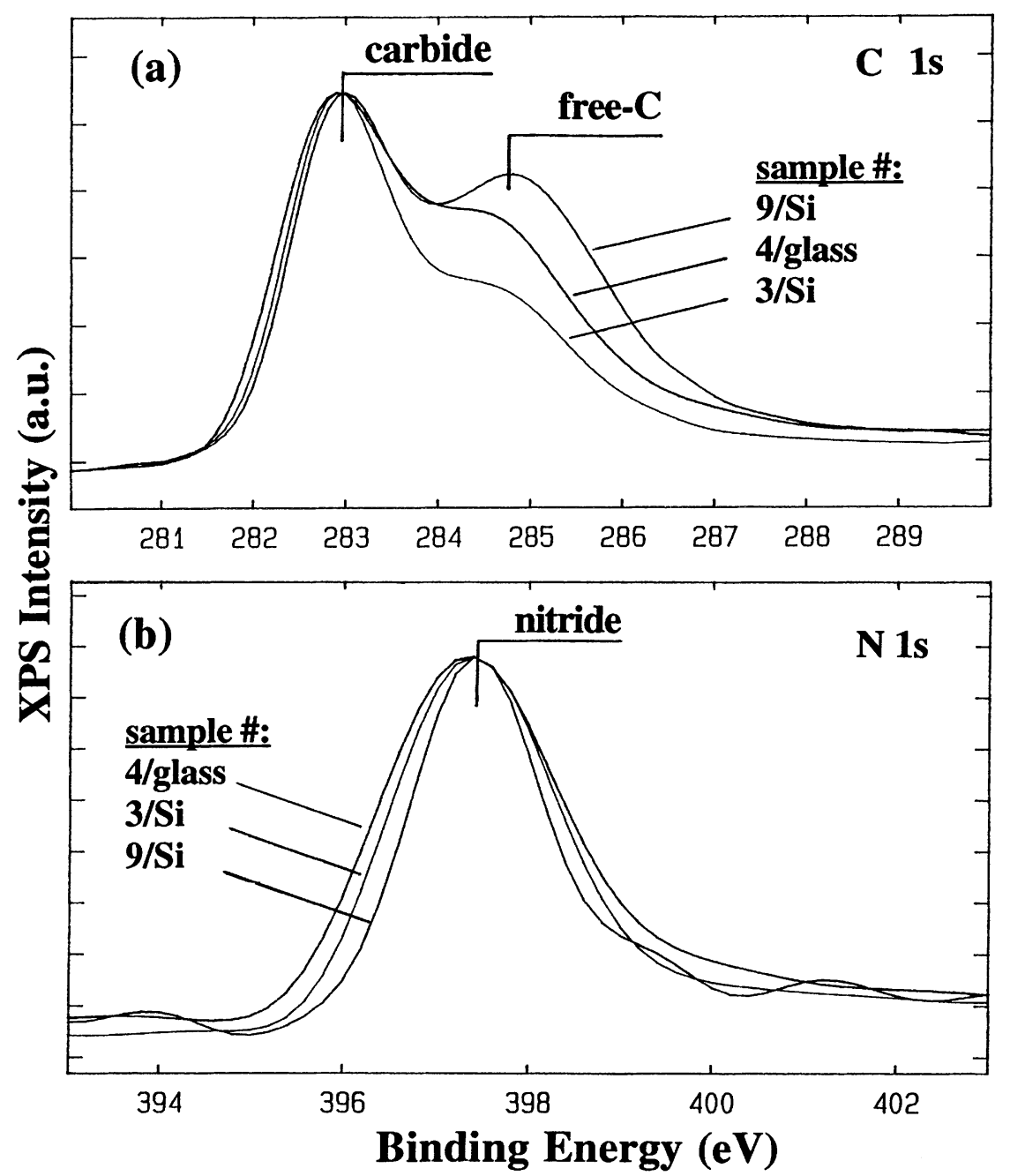

Figure 1 High-resolution C $1 s$ (a) and N $1 s$ (b) regions of XPS spectra of three samples prepared by MOCVD using $\mathrm{Cr}\left(\mathrm{NEt}_{2}\right)_{4}$ as single-source precursor under the conditions given in Table 2 (each sample is identified by its run number/substrate).

metals, and it has been found, for instance, that films deposited using $\mathrm{Ti}\left(\mathrm{NMe}_{2}\right)_{4}{ }^{6,7}$ and $\mathrm{Ti}\left(\mathrm{NEt}_{2}\right)_{4}{ }^{7}$ were heavily contaminated with carbon.

The films deposited at 683 and $793 \mathrm{~K}$ have very similar chemical bonding analyses. The binding energies of the $\mathrm{Cr} 2 p_{3 / 2}(574.4 \mathrm{eV}), \mathrm{N} 1 s(397.4 \mathrm{eV})$ and $\mathrm{C} 1 \mathrm{~s}(283.0 \mathrm{eV})$ levels are characteristic of chromium carbonitrides. ${ }^{1,31}$ Moreover, the C 1 s peak gives evidence for the presence of at least two forms of carbon: a carbidic form at $283.0 \mathrm{eV}$ and a free-carbon form (amorphous, graphitic or organic) at $284.5 \mathrm{eV}$ (Fig. 1). When the deposition temperature decreases to $573 \mathrm{~K}$, both the contribution of the free carbon and the full width at half maximum
(FWHM) of the $\mathrm{N} 1 s$ peak increase, revealing different environments for nitrogen and carbon. This indicates the probable incorporation of organic species which originate from an incomplete decomposition of $\mathbf{1}$. Deposition at $793 \mathrm{~K}$ using a stream of inert carrier gas leads to a slight increase of the freecarbon content of the films that is emphasized under an $\mathrm{H}_{2}$ partial pressure (Table 2). However since the FWHM of the $\mathrm{N} 1 s$ peak remains constant in these conditions, this increase of free carbon probably originates from amorphous or graphitic contributions rather than organic species.

As-deposited films are XRD-amorphous and have a shiny mirror-like surface morphology. The 


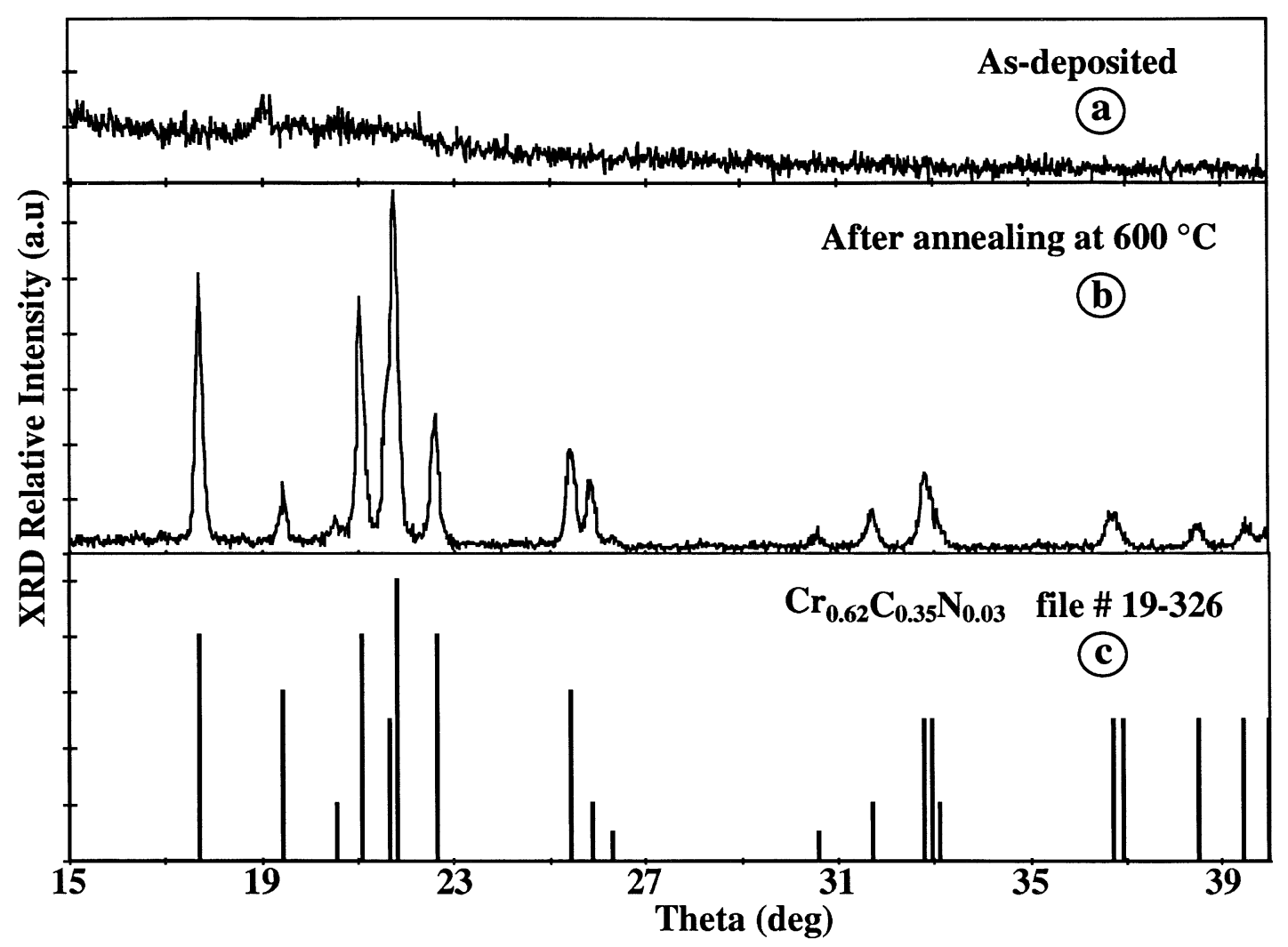

Figure 2 Grazing XRD patterns of a chromium carbonitride coating grown at $793 \mathrm{~K}$ on stainless steel (incident angle $2^{\circ}$ ): (a) asdeposited; (b) after annealing at $873 \mathrm{~K}$ under vacuum for $15 \mathrm{~h}$; (c) reference pattern of the ternary phase $\mathrm{Cr}_{0.62} \mathrm{C}_{0.35} \mathrm{~N}_{0.03}{ }^{32-34}$.

XRD patterns exhibit a broad hump centred at $\theta \simeq$ $21^{\circ}$ with a small peak at $\theta \simeq 19^{\circ}$ characteristic of the short-range order of the amorphous structure (Fig. 2). After annealing at $873 \mathrm{~K}$ under vacuum $\left(\sim 10^{-2} \mathrm{~Pa}\right)$ for $15 \mathrm{~h}$, the films deposited at $573 \mathrm{~K}$ are still XRD-amorphous, whereas those deposited at higher temperature crystallize. The different behavior of samples deposited at $573 \mathrm{~K}$ argues for an incorporation of organic species which are known to block the crystallization upon annealing. According to the typical film composition $\left(\mathrm{Cr}_{0.64} \mathrm{C}_{0.32} \mathrm{~N}_{0.04}\right)$, the XRD patterns match very well the pattern of the ternary phase $\mathrm{Cr}_{0.62} \mathrm{C}_{0.35} \mathrm{~N}_{0.03}$. ${ }^{32}$ No preferential orientation is observed from these diffraction patterns (Fig. 2). Because this orthorhombic ternary phase, also reported as $\mathrm{Cr}_{3}(\mathrm{C}, \mathrm{N})_{2}{ }^{33}$, has a small range of composition $^{34}$, there is no evidence for an excess of chromium in the films, e.g. in the form of chromium carbide.

The film resistivity decreases with increasing deposition temperature in the $573-793 \mathrm{~K}$ range

(C) 1998 John Wiley \& Sons, Ltd.
(Fig. 3). Typically, the resistivity of the film deposited at $793 \mathrm{~K}$ under vacuum reaches the relatively low value of $153 \mu \Omega \mathrm{cm}$, which is of the same order as that of chromium carbide ${ }^{35}$ and chromium carbonitride 4 thin films. The rapid increase in resistivity towards low-deposition temperature $(573 \mathrm{~K})$ is indicative, in spite of a broader dispersion of the experimental data, of a contamination of the film which could be associated once again with the presence of organic species, as was assumed from XPS analyses and annealing experiments, and proposed in an early study on chromium carbide thin films grown at low temperature. $^{35}$

Films grown at $793 \mathrm{~K}$ under $7.3 \times 10^{2} \mathrm{~Pa}$ using either $\mathrm{N}_{2}$ or $\mathrm{H}_{2}$ as carrier gas have a higher resistivity ( $\mathrm{ca} 800-900 \mu \Omega \mathrm{cm}$ ) than those grown under vacuum (Fig. 3). Since as-deposited films grown at this temperature with and without carrier gas are amorphous and have a very closely similar composition, the higher resistivity of those grown using a carrier gas is supposed to be due to a larger 


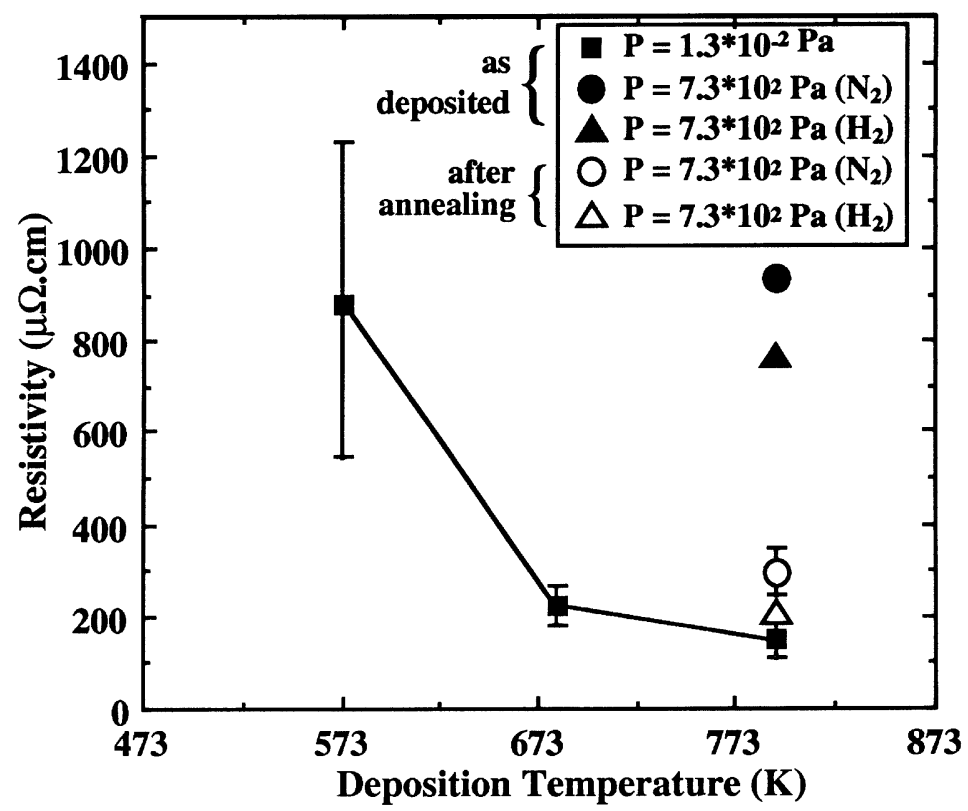

Figure 3 Electrical resistivity of chromium carbonitride thin films as a function of the deposition temperature and for different atmospheres as indicated in the inset.

contamination by free carbon, as supported by XPS data (Table 2). After annealing at $873 \mathrm{~K}$ for $15 \mathrm{~h}$ under vacuum, crystallization of these films occurs to form an orthorhombic single-phased structure and therefore resistivity decreases to $\mathrm{ca} 200 \mu \Omega \mathrm{cm}$.

\section{DECOMPOSITION MECHANISM}

Two quantitative NMR analyses of the by-products from MOCVD experiments performed under vacuum at $793 \mathrm{~K}$ have given reproducible results (in addition to $\mathbf{2}$ and $\mathbf{3}$ traces of an unidentified species giving a ${ }^{1} \mathrm{H}$ NMR singlet at $0.7 \mathrm{ppm}$ were always present in the NMR spectra with an intensity $\leq 10 \%$ of the integral value of the $\mathrm{CH}_{2}$ signal of 3 ): 1.83 and $1.89 \mathrm{~mol}$ of 2 and 1.60 and 1.64 mol of 3 per mol of $\mathbf{1}$ consumed (i.e. $\mathbf{2} / \mathbf{3}=1.15: 1$ ). This was found in very good agreement with two other nonquantitative analyses from ${ }^{1} \mathrm{H}$ relative intensities which have given $\mathbf{2 / 3}$ ratios of $1.12: 1$ and 1.17:1, confirming that this simpler method provides meaningful data.

It is well known that under vacuum intermolecular reactions are less likely than other decomposition pathways and, under CVD conditions, surface reactions play a major role. Therefore the primary pyrolysis mechanism certainly takes place on or very near the surface of the substrates. It is assumed to be an elimination reaction of the four $\mathrm{NEt}_{2}$ ligands of $\mathbf{1}$ involving the transfer of a hydrogen atom from one $\mathrm{NEt}_{2}$ group to another and leading to the equimolar formation of $\mathbf{2}$ and $\mathbf{3}$ according to the overall equation:

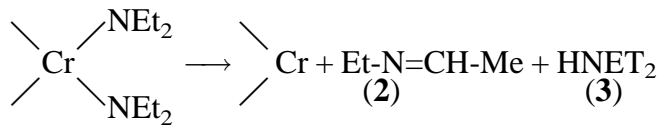

A radical mechanism for this elimination process $^{36}$ or participation of other sources of labile hydrogens, e.g. OH groups originating from initial surfaces, is less probable than a $\beta$-hydrogen elimination. The formation of a hydride or a metal-mediated H-transfer may be assumed to be the transition state, as depicted by Scheme 1 . Indeed, even if an hydride is an entropically favored intermediate, the low-energy vacant $d$-orbitals of chromium can produce bonding interactions with the transferring hydrogen atom, ${ }^{37}$ lowering the activation barrier for this transfer process and making an energetically accessible transition state. Such a concerted process is supported by previous results on the solid-state thermolysis of diethylamido complexes of tantalum, niobium and tungsten $^{21,38-40}$ which proceeded via an intramolecular metallation reaction of the $\mathrm{NEt}_{2}$ ligand with $\mathrm{HNEt}_{2}$ elimination and, subsequently, afforded a stable 


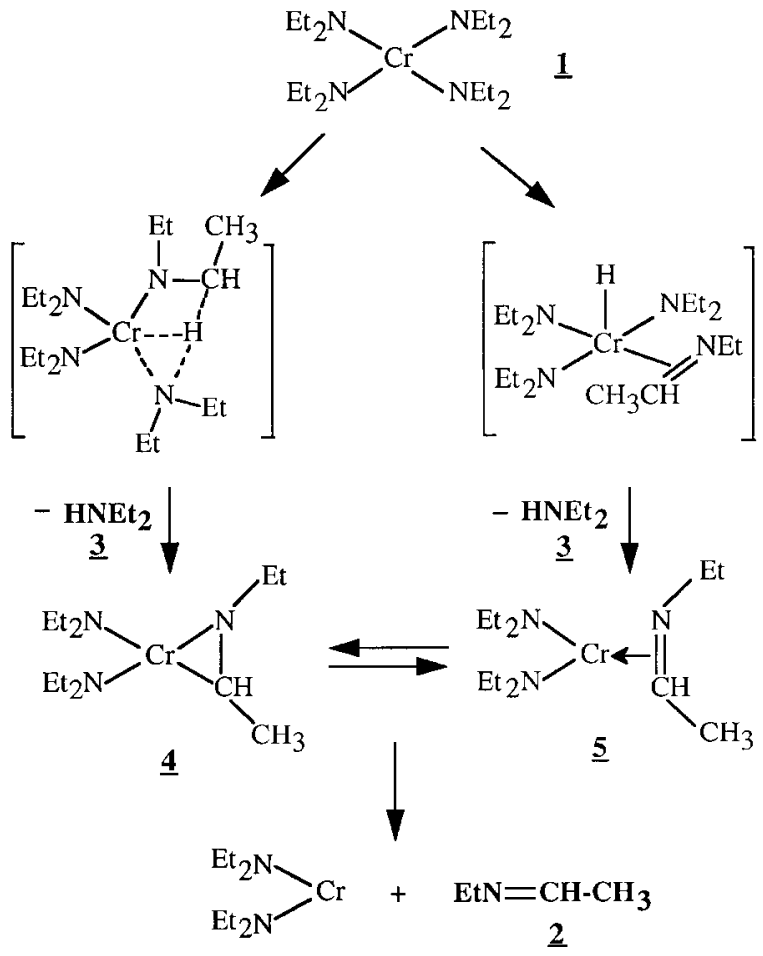

Scheme 1 Principal decomposition mechanism of $\mathrm{Cr}\left(\mathrm{NEt}_{2}\right)_{4}$ under low-pressure MOCVD conditions, showing two tentative transition states.

compound having a three-membered ring including a transition metal-carbon bond as in 4 (Scheme 1). The same complex has been postulated in several reports on the CVD reactions using $\mathrm{Ti}\left(\mathrm{NR}_{2}\right)_{4}{ }^{7,9,10,16}$ In both cases, i.e. in solid-state thermolysis and CVD conditions, partial doublebond character has been reported for the $\mathrm{C}-\mathrm{N}$ bond and the contribution of a structure like $\mathbf{5}$, which favors removal of $\mathrm{EtN}=\mathrm{CHMe}$, has previously been taken into consideration. The primary reaction pathway proposed in Scheme 1 is essentially heterogeneous and accounts for an equimolar ratio of $\mathbf{2}$ and $\mathbf{3 .}$

According to this mechanism pure chromium should be formed, whereas chromium carbonitride films with low nitrogen content were obtained in our MOCVD experiments. Furthermore, there is a slight discrepancy between the stoichiometry of Eqn [1] and the ratios of by-products trapped, since slightly less than 2 mol of both $\mathbf{2}$ and $\mathbf{3}$ were analyzed per mol of $\mathbf{1}$ consumed. However, assuming a total decomposition of $\mathbf{1}$ and taking into account the amount of $\mathbf{2}$ and $\mathbf{3}$ analyzed, we can estimate that roughly $90 \%$ of $\mathrm{NEt}_{2}$ ligands are removed by this principal mechanism. This is also consistent with another estimate based on a mass balance since, assuming a total decomposition of $\mathrm{Cr}\left(\mathrm{NEt}_{2}\right)_{4}$, the extent of carbon and nitrogen incorporation in a film with a typical composition $\mathrm{Cr}_{0.64} \mathrm{C}_{0.32} \mathrm{~N}_{0.04}$ is only in the range $2-3 \%$, indicating that most of the $\mathrm{NEt}_{2}$ groups must be cleanly removed from the deposition zone and then could be involved in such an elimination mechanism.

Then it is reasonable to assume that secondary reactions occur in the CVD process to account for the carbon and nitrogen incorporation in the growing layers. In regard to the number of $\mathrm{NEt}_{2}$ ligands involved, most of these reactions can be considered as minor processes, even if they lead, for instance, to $\sim 32$ at $\%$ of carbon in the films since, as mentioned above, this corresponds to carbon incorporation of only a few per cent.

As an example, in addition to the imine elimination reaction, the azametallacyclopropane species 4 can undergo other, different, decomposition pathways, for instance (i) via metal-carbon bond cleavage, elimination of light hydrocarbons, e.g. ethylene, and formation of an ethylimido complex, as described for $\mathrm{Ta}\left(\mathrm{NEt}_{2}\right)_{5} ;{ }^{21}$ and (ii) via metal-nitrogen bond cleavage, formation of $\mathrm{Cr}-$ $\mathrm{C}$ bonds and release of nitrogen containing volatile species (Scheme 2). The first route seems less

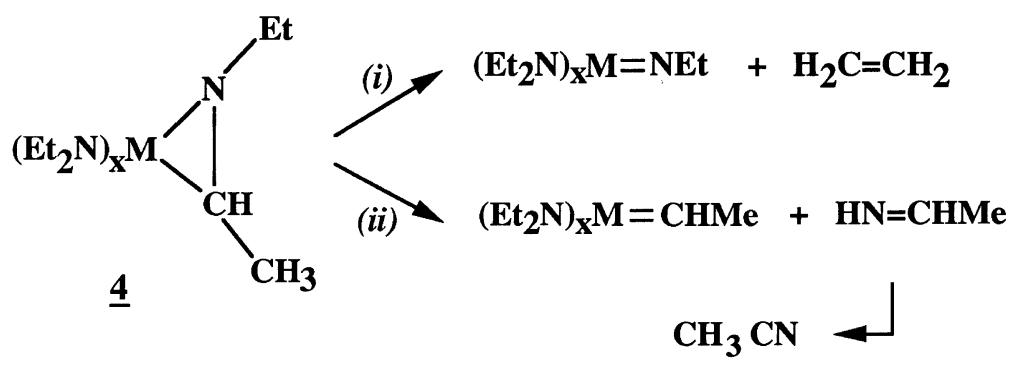

Scheme 2 Possible reaction pathways for the pyrolysis of $\mathrm{M}\left(\mathrm{NEt}_{2}\right)_{4}(\mathrm{M}=\mathrm{Cr}, \mathrm{V})$ which account for the incorporation of $\mathrm{C}$ and $\mathrm{N}$ into the films. 
probable since ethylene was not detected and the nitrogen content of the films, probably originating from the ethylimido complex, is only a few atoms per cent. Indeed, related organoimido complexes of tantalum ${ }^{41}$ and niobium ${ }^{42}$ were used successfully as single-source precursor for the growth of mononitrides, owing to the strong $\mathrm{M}=\mathrm{N}$ bonds. It is noteworthy that the reaction pathway (i) seems to be more favorable using $\mathrm{V}\left(\mathrm{NEt}_{2}\right)_{4}$ than using $\mathrm{Cr}\left(\mathrm{NEt}_{2}\right)_{4}$ because, under similar MOCVD conditions, the nitrogen content of the vanadium-based coatings is higher than than that of the chromiumbased ones and ethylene was observed as a byproduct in the decomposition of $\mathrm{V}\left(\mathrm{NEt}_{2}\right)_{4}$ whereas it was not with the Cr-derivative. ${ }^{43}$ Both decomposition side-reaction pathways of the azametallacyclopropane intermediate $\mathbf{4}$ are meaningful because, in the case of $\mathrm{V}\left(\mathrm{NEt}_{2}\right)_{4}$, they account for the formation of identified gaseous by-products, e.g. $\mathrm{C}_{2} \mathrm{H}_{4}$ and $\mathrm{CH}_{3} \mathrm{CN}^{43}$ (Scheme 2). Furthermore, in agreement with many reports on the CVD chemistry of $\mathrm{Ti}\left(\mathrm{NR}_{2}\right)_{4}$, we assume that the intermediate $\mathbf{4}$ is largely responsible for the carbon incorporation into the films, possibly by the route (ii). $^{7,9,10,16}$

Obviously, other mechanisms are possible to explain the increase in carbon content, such as a $\gamma-\mathrm{H}$ activation of $\mathrm{Cr}\left(\mathrm{NEt}_{2}\right)_{4}$ followed by an $\alpha-\mathrm{H}$ activation and leading to an increase in the $\mathrm{Cr}-\mathrm{C}$ bond order. However the mechanism proposed in Scheme 2 is supported by the identification of the by-products, specially using the vanadium derivative. ${ }^{43}$ Different mechanisms may be postulated when other gaseous species are detected, as mentioned hereinafter.

Although equal amounts of $\mathbf{2}$ and $\mathbf{3}$ should be produced by the primary $\mathrm{NEt}_{2}$ elimination mechanism proposed (Eqn [1]), ${ }^{1} \mathrm{H}$ NMR analyses give a by-product ratio $\mathbf{2} / \mathbf{3}=1.15: 1$ for deposition carried out at $793 \mathrm{~K}$ (run 3) and approximately the same value at $683 \mathrm{~K}$ (run 6), whereas it decreases to approximately $0.8: 1$ at $573 \mathrm{~K}$ (run 4). In deposition processes under $\mathrm{N}_{2}$ (run 9) and $\mathrm{H}_{2}$ (run 10) the 2/3 ratio was approximately $1.1: 1$ and new species were produced in addition to 2 and 3 but their identification was difficult due to overlapping of the various $\mathrm{CH}_{2}-\mathrm{CH}_{3}$ quartet-triplet signal patterns in the NMR spectra.

The pyrolysis of pure $\mathrm{HNEt}_{2}(3)$ was investigated in the MOCVD reactor using conditions similar to those which were used for the decomposition of $\mathrm{Cr}\left(\mathrm{NEt}_{2}\right)_{4}$ in order to determine whether it undergoes decomposition side-reactions which could contribute to the incorporation of the metalloid
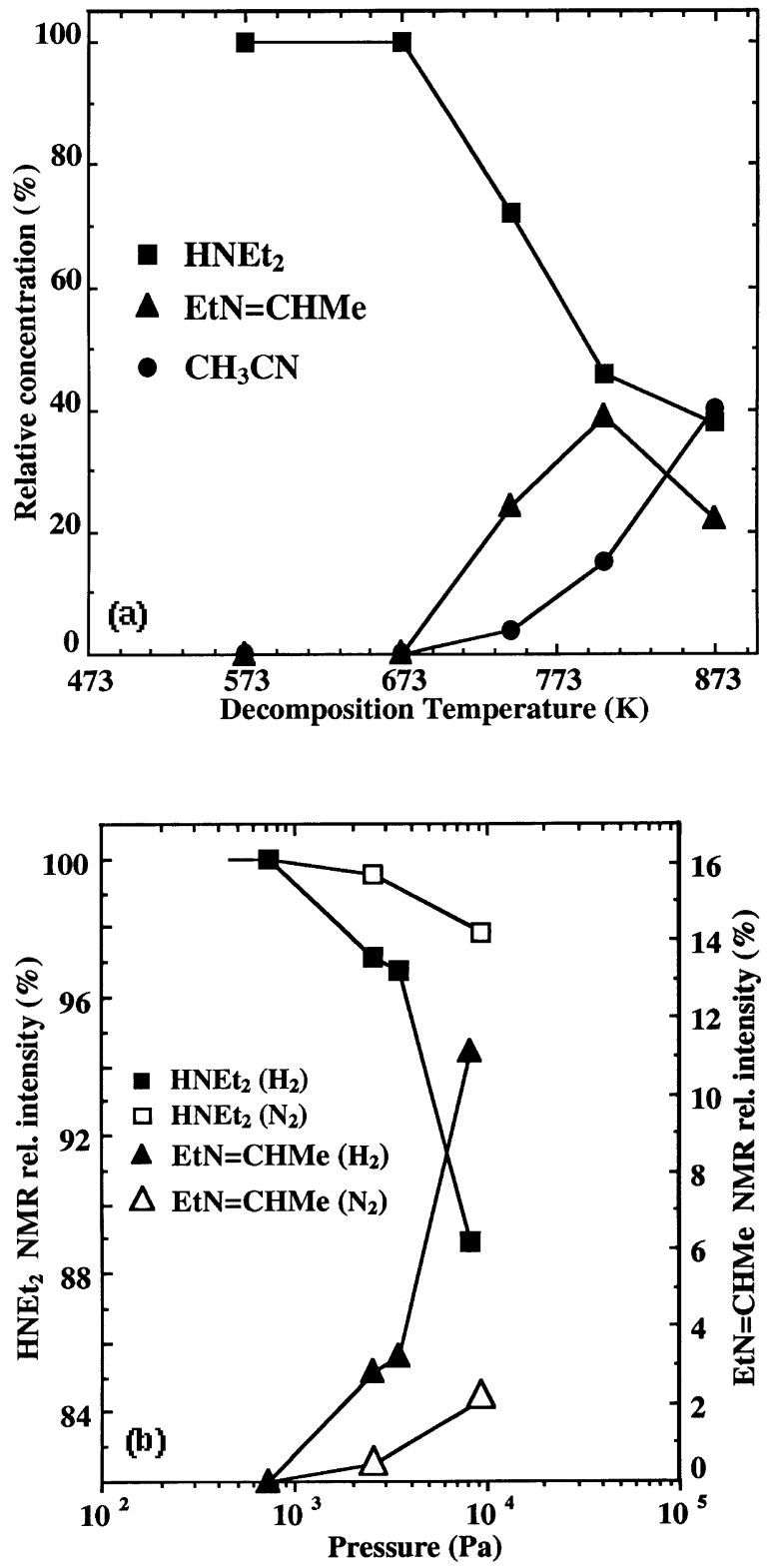

Figure 4 Relative concentration of the by-products trapped during the pyrolysis of $\mathrm{HNEt}_{2}$ as a function of (a) the temperature $(P \simeq 7 \mathrm{kPa})$ and (b) the total pressure $(T=793 \mathrm{~K})$ under $\mathrm{N}_{2}$ and $\mathrm{H}_{2}$ atmospheres. The relative concentrations were defined as $x_{i} / \Sigma x_{i}$ and were calculated from the ${ }^{1} \mathrm{H}$ integral values $\left(x_{i}\right)$ of the NMR spectra.

elements in the films and account for the variation of the $\mathbf{2 / 3}$ ratios with the temperature. Preliminary experiments performed using relatively high dwell times $(P \simeq 7 \mathrm{kPa})$ reveal that $2, \mathrm{CH}_{3} \mathrm{CN}$ and $\mathrm{C}_{2} \mathrm{H}_{4}$ are by-products of $\mathrm{HNEt}_{2}$ pyrolysis (Fig. 4a). The 
presence of $\mathbf{2}$ is not surprising since it was formed in the photolysis of $\mathrm{HNEt}_{2}{ }^{36}$ whereas the other byproducts were found in the pyrolysis of $\mathrm{H}_{2} \mathrm{NEt}{ }^{44}$ The ${ }^{1} \mathrm{H}$ NMR analysis of the gas trapped at the outlet of the reactor did not reveal any decomposition reactions at $793 \mathrm{~K}$ when $P \leq 7.3 \times 10^{2} \mathrm{~Pa}$, i.e. in the growth MOCVD conditions using $\mathrm{Cr}\left(\mathrm{NEt}_{2}\right)_{4}$ (Fig. 4b). Unfortunately, the influence of the nature of the substrate surface was not investigated and, consequently, an incorporation of metalloid elements by heterogeneous decomposition of $\mathrm{HNEt}_{2}$ on a growing chromium carbide layer is not excluded. At higher pressure, $\mathrm{HNEt}_{2}$ decomposition occurs and $\mathbf{2}$ was detected as the predominant by-product in an amount increasing with the total pressure (or the dwell time in the reactor), confirming the occurrence of the dehydrogenation reaction of $\mathbf{3}$.

At low decomposition temperatures of $\mathrm{Cr}\left(\mathrm{NEt}_{2}\right)_{4}$ $(573 \mathrm{~K})$, the lower concentration of 2 is probably due to an incomplete occurrence of the imine elimination reaction and subsequent partial incorporation of EtNCHMe ligands into the growing layers. This is supported by features of XPS spectra of the films deposited at $573 \mathrm{~K}$ which give evidence for incorporation of organic species, by contrast to those deposited at higher temperature (Fig. 1) and by their higher resistivities (Fig. 3). Furthermore, this organic contamination observed at low temperature probably blocks the crystallization of the coatings upon annealing at $873 \mathrm{~K}$. When using a stream of $\mathrm{H}_{2}$ or $\mathrm{N}_{2}$, the formation of new volatile species, in addition to $\mathbf{2}$ and $\mathbf{3}$, is probably due to heterogeneous side-reactions interfering with the removal of the ligands, which is more efficient under high vacuum. Such side-reactions could account for the higher incorporation of free carbon in the films.

\section{CONCLUSIONS}

Amorphous chromium carbonitride coatings with a low nitrogen content were deposited by lowpressure MOCVD in the relatively low temperature range 573-793 $\mathrm{K}$ using $\mathrm{Cr}\left(\mathrm{NEt}_{2}\right)_{4}$ as single-source precursor. This poor nitrogen incorporation agrees with the trends predicted by thermochemical calculations. When the films are grown at $573 \mathrm{~K}$, they are contaminated by organic species due to incomplete elimination of the ligands, which probably block their crystallization upon annealing and account for their high resistivity. The films

(C) 1998 John Wiley \& Sons, Ltd. deposited at higher temperature crystallize upon annealing at $873 \mathrm{~K}$ to form an orthorhombic ternary phase. The higher resistivity of as-deposited films grown at $793 \mathrm{~K}$ under higher pressure could be related to their higher free-carbon content. After annealing at $873 \mathrm{~K}$ under vacuum, crystallization occurs and resistivity decreases to the relatively low values measured for films as-grown under vacuum.

The major volatile by-products of the MOCVD reaction were analyzed by ${ }^{1} \mathrm{H}$ and ${ }^{13} \mathrm{C}$ NMR. Their amount and the quasi-equimolecular $\mathrm{EtN}=\mathrm{CHMe} /$ $\mathrm{HNEt}_{2}$ ratio suggest that most of the $\mathrm{NEt}_{2}$ ligands are removed by a stepwise mechanism involving the formation of an azametallacyclopropane intermediate. The incorporation of metalloid elements in the film probably originates from decomposition side-reaction of this intermediate. Recent results using the vanadium analog ${ }^{43}$ and literature data $9,9,10,16$ suggest that this decomposition mechanism probably occurs with other diethylamido complexes of transition metals when they are used as single-source precursors in MOCVD.

Acknowledgments We gratefully acknowledge Drs F. Schuster and C. Bernard for their contribution to the thermodynamic calculations and L. Dumitrescu for assistance in resistivity measurements.

\section{REFERENCES}

1. F. Schuster, F. Maury, J. F. Nowak and C. Bernard, Surf. Coatings Technol. 46, 275 (1991).

2. F. Maury, Chem. Vap. Deposition 2, 113 (1996).

3. F. Maury, Appl. Organometal. Chem. 6, 619 (1992).

4. N. M. Rutherford, C. E. Larson and R. L. Jackson, Mat. Res. Soc. Symp. Proc. 131, 439 (1989).

5. D. V. Baxter, M. H. Chisholm, G. J. Gama, A. L. Hector and I. P. Parkin, Chem. Vap. Deposition 1, 49 (1995).

6. K. Sugiyama, S. Pac, Y. Takahashi and S. Motojima, J. Electrochem. Soc. 122, 1545 (1975).

7. R. M. Fix, R. G. Gordon and D. M. Hoffman, Chem. Mater. 2, 235 (1990)

8. P. Bonnefond, R. Feurer, A. Reynes and F. Maury, In: Advances in Inorganic Films and Coatings (Proc. of Topical Symposium 1 of the 8th CIMTEC-World Ceramics Congress and Forum on New Materials), Vincenzini, P. (ed.), Techna, Faenza, Italy, 1995, p. 207.

9. D. M. Hoffman, Polyhedron 13, 1169 (1994).

10. C. I. M. A. Spee, J. P. A. M. Driessen and A. D. Kuypers, J. Phys. IV, Coll. C5, 5, 719 (1995).

11. R. Fix, R. G. Gordon and D. M. Hoffman, Chem. Mater. 3, 1138 (1991).

12. C. M. Truong, P. J. Chen, J. S. Corneille, W. S. Oh and D. W. Goodman, J. Phys. Chem. 99, 8831 (1995).

Appl. Organometal. Chem. 12, 189-199 (1998) 
13. B. H. Weiller and B. V. Partido, Chem. Mater. 6, 260 (1994).

14. J. A. Prybyla, C. M. Chiang and L. H. Dubois, J. Electrochem. Soc. 140, 2695 (1993).

15. B. H. Weiller, Chem. Mater. 7, 1609 (1995).

16. L. H. Dubois, B. R. Zegarski and G. S. Girolami, J. Electrochem. Soc. 139, 3603 (1992).

17. A. Intemann, H. Koerner and F. Koch, J. Electrochem. Soc. 140, 3215 (1993).

18. R. Fix, R. G. Gordon and D. M. Hoffman, J. Am. Chem. Soc. 112, 7833 (1990).

19. R. Fix, R. G. Gordon and D. M. Hoffman, Chem. Mater. 5, 614 (1993).

20. H. Burger and H. J. Neese, J. Organometal Chem. 21, 381 (1970).

21. Y. Takahashi, N. Onoyama, Y. Ishikawa, S. Motojima and K. Sugiyama, Chem. Lett. 525 (1978).

22. J. S. Basi, D. C. Bradley and M. H. Chisholm, J. Chem. Soc. (A) 1433 (1971).

23. M. P. Seah, Thin Solid Films 81, 279 (1981).

24. C. Stevens and N. De Kimpe, J. Org. Chem. 58, 132 (1993).

25. C. J. Pouchert and J. Behnke, The Aldrich Library of ${ }^{13} \mathrm{C}$ and ${ }^{1}$ H FT NMR Spectra, 1st edn, Aldrich, Milwaukee, WI, 1993.

26. P. M. Jeffries, L. H. Dubois and G. S. Girolami, Chem. Mater. 4, 1169 (1992)

27. C. Bernard, Y. Deniel, A. Jacquet, P. Vay and M. Ducarroir, J. Less Common. Met. 40, 165 (1975).

28. F. Schuster, M. C. Schouler, C. Bernard, F. Maury, R. Morancho and J. F. Nowak, Proc. 11th Int. Conf. on CVD, Spear, K. E. and Cullen, G. W. (eds), The Electrochemical Society, Pennington, NI, 1990, pp.113-119.

29. Scientific Group Thermodata Europe Databank (SGTE), Saint Martin d'Hères, France.
30. J. F. Nowak, C. Duret-Thual, F. Maury and D. Oquab, Proc. Int. Coll. on Wear and Resistant Materials, Bull. Cercle d'Etude des Métaux 15, 14.1 (1987).

31. F. Maury and F. Ossola, Thin Solid Films 207, 82 (1992).

32. Joint Committee on Powder Diffraction Standards (JCPDS), International Center for Diffraction Data, Swarthmore, PA, 1992, file no. 19-326.

33. P. Ettmayer, G. Vinek and H. Rassaerts, Monatsh. Chem. 97, 1258 (1966).

34. R. Kieffer, P. Ettmayer and T. Dubsky, Z. Metallkde. 8, 560 (1967).

35. N. G. Anantha, V. Y. Doo and D. K. Seto, J. Electrochem. Soc. 118, 163 (1971).

36. G. De Stefano and J. Heicklen, J. Phys. Chem. 90, 4637 (1986).

37. T. R. Cundari and M. S. Gordon, J. Am. Chem. Soc. 115, 4210 (1993)

38. C. Airoldi, D. C. Bradley and G. Vuru, Transition Met. Chem. 4, 64 (1979).

39. W. A. Nugent, D. W. Ovenall and S. J. Holmes, Organometallics 2, 161 (1983).

40. J. M. Mayer, J. C. Curtis and J. E. Bercaw, J. Am. Chem. Soc. 105, 2651 (1983).

41. H. -T. Chiu and W. P. Chang, J. Mater. Sci. Lett. 11, 96 (1992).

42. C. H. Winter, K. C. Jayaratne and J. W. Proscia, Mater. Res. Soc Symp. Proc. 327, 103 (1994).

43. P. Bonnefond, R. Feurer, A. Reynes, F. Maury, B. Chansou, R. Choukroun and P. Cassoux, J. Mater. Chem. 6, 1501 (1996).

44. F. J. Lovas, F. O. Clark and E. Tiemann, J. Chem. Phys. 62, 1925 (1975). 